\title{
THE EFFECTS OF TIME PRESSURE AND SITUATIONAL CONSTRAINS ON THE PROACTIVE WORK BEHAVIOR THROUGH PSYCHOLOGICAL EMPOWERMENT AS A MEDIATOR
}

\author{
Kusbadini Wahyu, Fajrianthi \\ Department of Industrial and Organizational Psychology, Faculty of Psychology, \\ University of Airlangga, Surabaya, Indonesia \\ *E-mail: wahyu.kusbadini@gmail.com
}

\begin{abstract}
Proactive work behavior has become a necessity for many modern, dynamic and global companies, in which employees are required to exhibit proactive work behavior in order to successfully achieve both individual and organizational outcomes. A person's behavior is not only influenced by the nature inherent in him or her, but a person's traits interact with his or her environmental situation. Emphasizing negative contextual factors, this study measured the effects of job stressors (time pressure and situational constraints) on the proactive work behavior through psychological empowerment as a mediator. The samples used were 140 salespeople in various business sectors. The sampling technique used was accidental sampling technique and the data collection tool was in the form of a questionnaire using a proactive work behavior scale $(\alpha=0,916)$; time pressure $(\alpha=0,845)$; situational constraints $(\alpha=0,881)$; psychological empowerment $(\alpha=0,898)$. The data analysis used was partial least square by means of SmartPLS 3.0 program. The findings indicated that the job stressor of time pressure had a positive effect on the proactive work behavior, while the job stressor of situational constraints had a negative effect on the proactive work behavior. Related to the mediating role, the psychological empowerment did not have a mediating role in the relationship between those two job stressors and the proactive work behavior.
\end{abstract}

\section{KEY WORDS}

Proactive work behavior, psychological empowerment, situational constrains, time pressure.

Many companies require their employees to take active and proactive steps by identifying future opportunities to achieve stable long-term goals in an unpredictable environment (Crant, 2000). The impact of proactive work behavior is very beneficial for both employees and companies. The proactive work behavior is the most important determinant of the success and improvement of company effectiveness (Crant, 2000; Griffin, Neal \& Parker, 2007). Proactive work behavior is takes the initiative to improve the current situation or create new things involving the status quo, rather than just passively accepting the current conditions (Carnt, 2000). Changes and demands to be proactive can cause an increase in employee work stress (Sonnentag \& Spychala, 2012).

Previous studies showed a negative relationship between job stressors and employee performance, meaning that an increase in the job stressors is associated with a direct or indirect decrease in the employee performance (Jex, 1998). Workload and time pressure affected the employee performance through poor health conditions (Jex, 1998). In addition, the situational constraints were consistently associated with poor job performance (Ellis, 2012). The relationship between the job stressors and employee performance still seems weak and inconsistent (Jex, 1998).

Recently, some empirical studies have proven that the job stressors do not always have a damaging and bad impact on one's work results or behavior. In their study, Fay and Sonnentag (2002) found that the job stressors were positively associated to taking personal initiative. Fritz and Sonnentag (2009) showed that the job stressors and positive affections predicted the proactive work behavior on the same day and the following day. Sonnentag and Spychala (2012) actually found different results that the situational constraints were not related to the proactive work behavior and had a negative relationship with role breadth self- 
efficacy while the job control and time pressure were positively related to the proactive work behavior through the role breadth self-efficacy.

The inconsistency of the results of the previous studies is important to reexamine the relationship between the job stressors and proactive work behavior. This study focused on two job stressors, namely the time pressure and situational constraints on the proactive work behavior. Both job stressors have been proven to have the strongest effects in the work settings and are often associated with a decrease in the employee health and well being (Jex, 1998; De Lange, et al., 2003, in Fritz \& Sonnentag, 2009). However, the employees must continue to strive to achieve the work targets that have been set because it will affect their performance achievements and overall company effectiveness. One strategy to achieve these goals is that the employees must demonstrate the proactive work behavior (Fritz \& Sonnentag, 2009).

This study used the psychological empowerment as a mediator variable. The psychological empowerment is intrinsic motivation that reflects one's orientation and how individuals who have confidence in their ability to accomplish their role in a positive way (Spreitzer, 1995). Psychologically, the employees who feel the meaningfulness of their work will show more sense of responsibility for their work so that they can provide positive work results for themselves, work units and companies (Luth, 2012). Active employees definitely want to create their work role and increase their motivation so that it results in higher proactive work behavior (Searle, 2011). Organ (1988, in Tastan \& Serinkan, 2013) also suggests that for the employees, the most likely way to complete their obligations is by showing the proactive work behavior.

\section{LITERATURE REVIEW}

Griffin, Neal and Parker (2007) classifies individual task behavior, team member behavior and organizational member behavior into proficiency, adaptivity and proactivity. The proactive work behavior is the extent to which the individual takes action independently to anticipate or initiate changes in work systems or work roles (Griffin, et al., 2007). There are three dimensions to identify the proactive work behavior, first, the proactive as individual task (directed towards an individual's work, such as improving one's work procedures), second, proactive as team member (directed to help the team and other team members, such as improving the way the team works) and third, proactive as an organizational member (directed towards broader system changes or organizational practices such as improving the systems for knowledge management in the organizations).

Job stressors can be defined as the pressure experienced by individuals as a result of external factors such as the characteristics of work such as the demands of their work and constraints of other organizations (Kahn et al., 1964, in Essiam, Mensah, Kudu \& Gyamfi, 2015). Semmer (1984) measures the job stressors that only focus on a single aspect but recurrent chronic aspects of his work.

Time pressure is a measure of the amount of work felt related to speed and number of tasks (Spector \& Jex, 1998). Sonnentag and Spychala (2012) suggest that time pressure is too many tasks that must be completed in a short time. Time pressure is characterized by how many tasks must be done in a given period (Semmer, et al., 1996) and included as a challenge stressors, namely stress that encourages a person to achieve goals, learning and development (Cavanaugh, Boswell, Roehling \& Boudreau, 2000). Individuals will be challenged to overcome obstacles that provide opportunities for learning (Luth, 2012). Time pressure is the workload that drives it to take action and change something to reduce stress.

$\mathrm{H} 1 \mathrm{a}$ : Time pressure will be positively related to proactive work behavior.

$\mathrm{H} 1 \mathrm{~b}$ : Time pressure will be positively related to psychological empowerment.

H3c: The relationship between time pressure and proactive work behavior will be mediated by psychological empowerment.

Situational or organizational constraints represent situations or things that prevent employees from showing their abilities as an effort to improve job performance (Spector \& Jex, 1998). Situational constraints are characterized by faulty equipment, incomplete 
information, inadequate procedures or perhaps other people's interruptions (Spector \& Jex, 1998). Individuals work with poor quality work materials, do not get the work material needed, work requirements and procedures are not appropriate because of situational constraints (Semmer, et al., 1996). Situational constraints are classified as hindrance stressors, namely stress which inhibits the achievement of one's tasks or goals (Cavanaugh, et al., 2000).

$\mathrm{H} 2 \mathrm{a}$ : Situational constraints will be negatively related to proactive work behavior.

$\mathrm{H} 2 \mathrm{~b}$ : Situational constraints will be negatively related to psychological empowerment.

$\mathrm{H} 2 \mathrm{c}$ : The relationship between situational constraints and proactive work behavior will be mediated by psychological empowerment.

According to Spreitzer (1995), the psychological empowerment as an individual's intrinsic motivation to the task resulting in the emergence of the feelings capable of actively carrying out and controlling his/her work role manifested in four cognitions: meaning, selfdetermination, competence and effect. Thomas and Velthouse (1990) define psychological empowerment as a set of cognitions that are influenced by the work environment to help create an active orientation towards one's work. Empowerment not only follows the judgment of individuals from their work assignments but also depends on contextual factors, such as input from superiors and coworkers. The psychological empowerment is conceptualized as an active motivation construct instead of passive motivation construct and orientation for work roles.

H3: Psychological empowerment will be postively related to proactive work behavior.

\section{METHODS OF RESEARCH}

We collected data with questionnaires in various business sectors (banking, insurance, manufacturing, automotive, hospitality, telecommunication, and others). The samples of this study were 140 salespeople A total of $43.6 \%$ were men and $54.4 \%$ were women, the average age was 21-30 years and the average length of work ranged from 1-3 years. Concerning education, $71.4 \%$ of the employees held a university degree.

We assessed proactive behavior using five point Likert scales from 1 (fully disagree) to 5 (fully agree) with the nine-item scale developed by Griffin et al. (2007). We assessed job stressors (time pressure and situational constraints) with self-report scales developed by Semmer (1984). We measured time pressure with five items with possible answers from 1 (never) to 5 (very often) and we assessed situational constraints with five items, which concern situations characterized by malfunctioning or incomplete equipment, tools, or information. We assessed psychological empowerment by Spreitzer's (1995) with 12 item to measure the four dimensions of psychological empowerment. The overall scale exhibited adequate internal consistency (proactive work behavior $(\alpha=0,916)$; time pressure $(\alpha=$ $0,845)$; situational constraints $(\alpha=0,881)$; psychological empowerment $(\alpha=0,898)$ ).

\section{RESULTS AND DISCUSSION}

The data analysis used was Partial Least Square (PLS) to predict the relationship between the constructs and be able to be used as a confirmation theory to build relationship that has not have theoretical foundation or for testing propositions. The purpose of this study is to explain the effect of time pressure and situational constrains on proactive work behavior with psychological empowerment as a mediator.

Table 1 - Means, Standard Deviation, and Correlation among Variables

\begin{tabular}{cccccc}
\hline $\mathrm{n} / \mathrm{n}$ & Mean & St. Dev & Adj. R2 & CR & AVE \\
\hline Time pressure & 16.29 & 3.65 & & .87 & .572 \\
Situational constrains & 15.23 & 3.67 & & .92 & .707 \\
Psychological empowerment & 48.54 & 8.20 & .54 & .94 & .578 \\
Proactive work behavior & 36.96 & 5.07 & .79 & .92 & .552 \\
\hline
\end{tabular}

St. Dev = standard deviation; Adj. R2 = adjusted R-squared; $C R=$ composite reliability; $A V E=$ average variance extracted. 
Table 2 - Model Results

\begin{tabular}{llll}
\hline Path & $t$-values & $p$-values & Comment \\
\hline TPressure $\rightarrow$ Proactive & 7.48 & .000 & Hypothesis 1a supported \\
TPressure $\rightarrow$ PsyEmpower & 3.52 & .001 & Hypothesis 1b supported \\
SConstrains $\rightarrow$ Proactive & -6.89 & .000 & Hypothesis 2a supported \\
SConstrains $\rightarrow$ PsyEmpower & -5.17 & .000 & Hypothesis 2b supported \\
PsyEmpowerment $\rightarrow$ Proactive & 3.75 & .000 & Hypothesis 3 supported \\
TPressure $\rightarrow$ PsyEmpower $\rightarrow$ Proactive & 2.53 & .012 & Hypothesis 1c not supported \\
SConstrains $\rightarrow$ PsyEmpower $\rightarrow$ Proactive & 3.18 & .002 & Hypothesis 2c not supported \\
\hline
\end{tabular}

TPressure = time pressure; SConstrains = situational constrains; PsyEmpower $=$ psychological empowerment; Proactive $=$ proactive work behavior $. p<.05$.

Psychological empowerment is postively and signifanctly related to proactive work behavior $(p=.000, t=3.75)$, supporting $\mathrm{H} 3$. Consistent with $\mathrm{H} 1 \mathrm{a}$ and $\mathrm{H} 1 \mathrm{~b}$, time pressure was positively related to proactive work behavior $(p=.001, t=7.48)$ and we found a significant direct positive relation between time pressure and psychological empowerment $(p$ $=.000, t=3.52$ ). The positive indirect relation between time pressure and proactive work behavior via psychological empowerment was not significant $(p=.012, t=2.53$ ). Hypothesis 1c was not supported. Situational constrains were negatively and signifanctly related to proactive work behavior $(p=.000, t=-6.89)$ and pyschological empowerment $(p=.000, t=$ - 5.17). $\mathrm{H} 2 \mathrm{a}$ and $\mathrm{H} 2 \mathrm{~b}$ was supported. The indirect relation between situational constraints and proactive behavior via psychological empowerment was not significant $(p=.002, t=$ 3.18). Hypothesis $\mathrm{H} 3 \mathrm{c}$ was not supported.

Time pressure showed positif relation with proactive work behavior. The findings of the above study were consistent with previous studies, Ohly, et al. (2006); Fay \& Sonnentag, 2002; Ellis (2012) which found that there was a positive relationship between the time pressure and proactive work behavior. LePine, et al. (2005) suggests that some job stressors, such as the time pressure, can be positively overcome by individuals so that it leads to behavior and confidence in the personal achievement according to the goals set. Individuals who feel the time pressure as a challenge and challenge assessment will actively demonstrate proactivity in the workplace. The time pressure can be described as overtaxing regulations, requiring more resources to quickly complete work and increased energy to ensure the goal achievements (Ohly \& Fritz, 2010).

Situational constrains showed negatif relation with proactive work behavior. The findings of this study indicated a negative and significant direct effect of the situational constraints on the proactive work behavior. Situational constraints are a type of hindrance stressors that has a negative relationship in fulfilling the work so that it affects the individual performance (LePine, et al., 2005). The findings of this study were different from the findings of several existing studies, such as studies conducted by Fritz and Sonnentag (2009); Fay and Sonnentag (2002) which revealed that there was a positive relationship where the high situational constraints and time pressure were associated with higher proactive work behavior levels. The differences in the findings between this study and several other studies might be caused by the differences in the characteristics of the research subjects and differences in the possessed internal motivation.

Psychological empowerment showed positif relation with proactive work behavior. Psychological empowerment increases the employees' work role to engage in the proactive work behavior (Searle, 2011). Huang (2017) suggests that the psychological empowerment is positively related to the proactive work behavior, i.e. the employees who have stronger empowerment perception than other employees will demonstrate the proactive work behavior. In his study, Huang (2012) also stated that the psychological empowerment was an important antecedent for one's proactive work behavior by finding feedback. In the mediating role, the psychological empowerment did not have a mediating role between the effects of the job stressors namely the time pressure and situational constraints on the proactive work behavior. 


\section{CONSLUSION AND SUGGESTIONS}

The findings indicated that the work stressor of time pressure had a positive effect on the proactive work behavior, while the work stressor of situational constraints had a negative effect on the proactive work behavior. Related to the mediating role, the psychological empowerment did not have a mediating role in the relationship between those two work stressors and the proactive work behavior. Although providing additional insight by extending the previous studies, this study also has several limitations.

For further research, it is expected that it can add personality factors as individual characteristic factors. This is to find out whether the effects produced are as strong as the effect of the proactive personality on the employees' proactive work behavior. Secondly, the development of the literature and research on one's proactivity has resulted in various different approaches. Nevertheless, there is no agreement to date regarding the appropriate approach to measure proactive as the proactive work behavior. For further research, it is also expected that it can use different theories and dimensions of the proactive work behavior to enrich the findings of the previous studies. Third, in this study, the proactive work behavior data were collected from only one source, namely the employees. For further research, it is also expected that it can use two data sources, namely employees and ratings from superiors or coworkers to avoid bias.

\section{REFERENCES}

1. Cavanaugh, M.A., Boswell, W.R., Roehling, M.V., \& Boudreau, J.W. (2000). An empirical examination of self-reported work stress among US managers. Journal of Applied Psychology, 85(1): 65-74.

2. Crant, J.M. (2000). Proactive behavior in organizations. Journal of Management, 26 (3), 435-462.

3. Crawford, E.R., LePine, J.A., \& Rich, B.L. (2010). Linking job demands and resources to employee engagement and burnout: A theoretical extension and meta-analytic test. Journal of Applied Psychology, 95(5): 834-848.

4. Ellis, A.M. (2012). The role of psychological resources in the relationship between work stressors and proactive behavior. Dissertations and Theses. Paper 770.

5. Fay, D., \& Sonnentag, S. (2002). Rethinking the effects of stressors: A longitudinal study on personal initiative. Journal of Occupational Health Psychology, 7, 221-234.

6. Frese, M., \& Fay, D. (2001). Personal initiative (PI): An active performance concept for work in the 21st century. Research in Organizational Behavior, 23, 133-187.

7. Frese, M., \& Zapf, D. (1994). Action as the core of work psychology: A German approach. Journal Industrial and Organizational Psychology, 4, 271-340.

8. Fritz, C., \& Sonnentag, S. (2009). Antecedents of day-level proactive behavior: A look at job stressors and positive affect during the workday. Journal of Management, 35, 94-111.

9. Griffin, M.A., Neal, A., \& Parker, S.K. (2007). A new model of work role performance: Positive behavior in uncertain and interdependent contexts. Academy of Management Journal, 50 (2), 327-347.

10. Huang, J.T. (2012). Be proactive as empowered? The role of trust in one's supervisor in psychological empowerment, feedback seeking, and job performance. Journal of Applied Social Psychology, 42, 103-E127.

11. Huang, Jiatao. (2017). The relationship between employee psychological empowerment and proactive behavior: Self-efficacy as mediator. Social Behavior and Personality, 45 (7), 1157-1166.

12. Jex, S.M. (1998). Stress and job performance: Theory, research, and implications for managerial practice. Thousand Oaks, CA: Sage.

13. Kammeyer-Mueller, J.D., \& Wanberg, C.R. (2003). Unwrapping the organizational entry process: Disentangling multiple antecedents and their pathways to adjustment. Journal of Applied Psychology, 88 (5), 779-794. 
14. LePine, J., Podsakoff, N., \& LePine, M. (2005). A meta-analytic test of the challenge stressor-hindrance stressor framework: An explanation for inconsistent relationships among stressors and performance. Academy of Management Journal, 48, 764-775.

15. Luth, Matthew. (2012). The bright and dark sides of empowerment: Linking psychological empowerment and job stressors to proactive and counterproductive work behaviors. Theses, Dissertations, United States: Univ of Kansas.

16. Ohly, S., Sonnentag, S., \& Pluntke, F. (2006). Routinization, work characteristics and their relationships with creative and proactive behaviors. Journal of Organizational Behavior, 27, 257-279.

17. Ohly, S., \& Fritz, C. (2010). Work characteristics, challenge appraisal, creativity and proactive behavior: A multi-level study. Journal of Organizational Behavior, 31, 543-565.

18. Searle, Travis P. (2011). A multilevel examination of proactive work behaviors: contextual and individual differences as antecedents. Theses, Dissertations, \& Student Scholarship: Agricultural Leadership, Education \& Communication Department. 20. http://digitalcommons.unl.edu/aglecdiss/20.

19. Seibert, S.E., Wang, G., \& Courtright, S.H. (2011). Antecedents and consequences of psychological and team empowerment in organizations: A Meta-Analytic Review. Journal of Applied Psychology, 96 (5), 981-1003.

20. Semmer, N. (1984). Stressbezogene Tätigkeitsanalyse [Stress-oriented activity analysis: psychological research on the analysis of stress at work]. Weinheim, Germany: Beltz.

21. Semmer, N., Zapf, D., \& Greif, S. (1996). "Shared job strain": A new approach for assessing the validity of job stress measurements. Journal of Occupational and Organizational Psychology, 69, 293-310.

22. Sonnentag, S., \& Spychala, A. (2012). Job control and job stressors as predictors of proactive work behavior: is role breadth self-efficacy the link?. Human Performance, 25, 412-431.

23. Spector, P.E. \& Jex, S.M. (1998). Development of four self-report measures of job stressors and strain: Interpersonal conflict at work scale, organizational constraints scale, quantitative workload inventory, and physical symptoms inventory. Journal of Occupational Health Psychology, 3, 356-367.

24. Spreitzer, G.M. (1995). Psychological empowerment in the workplace: Dimensions, measurement, and validation. Academy of Management Journal, 38 (5), 1441-1465.

25. Tastan, S.B., \& Serinkan, C. (2013). An empirical research on the relationship between individuals' psychological empowerment and voluntary performance behaviors: an assessment of the combination of pyschological power and intimate will. Journal of Global Strategic Management, 13, 100-124.

26. Thomas, K.W., \& Velthouse, B.A. (1990). An "interpretaive" mdoel of intrinsic task motivation. Academy of Management Review, 15 (4), 666-681. 